\title{
DIE HEILIGE GEES EN DIE ONTSTAAN EN VERSTAAN VAN \\ DIE NUWE TESTAMENT
}

Ds. B. J. de Klerk

\section{Inleiding}

\subsection{Bepaal die verstaan die ontstaan van die N.T.?}

Ernst Käsemann', in 'n sekere sin die vader van die aktualistiese kanonbeskouing, sluit by Luther aan wat sê die norm vir kanonbeoordeling is of Christus gepreek word. Hy soek die kanonisiteit van die Nuwe Testament daarin dat Christus Hom telkens weer aktueel in die gebeure van die prediking laat hoor. Die Woord van God word in hierdie aktuele gebeure gehoor. Ebeling ${ }^{2}$ sê: in die omgang met die Skrif realiseer die Skrif sy outoriteit.

Hierdie aktualistiese beskouing van die kanon bring ten diepste dit mee: Die Kanon ontstaan by die verstaan van die Nuwe Testament. Of anders gesê: Die verstaan van die Skrif bepaal die ontstaan van die Kanon.

Hier word van 'n bepaalde voorveronderstelling uitgegaan, $\mathrm{nl}$. dat die Bybel nie sy eie verstaankodes het nie. Vorster ${ }^{3}$ sê dat daar vir 'n korrekte verstaan en interpretasie van die N.T. nie 'n teologiese interpretasie of 'n aparte hermeneutiek as addisionele verstaanmodel nodig is nie. Hy neem nooit enige Skrifuitspraak in aanmerking nie as hy gedagtes uitspreek rondom die interpretasie van die N.T.

Die beginsels wat in die verstaan van die Skrif aangewend word, sal bepalend wees vir dit wat in die Bybel „oorbly" as kanon vir die mens (in die "nuwe" wêreld).

\subsection{Die Heilige Gees en die ontstaan en verstaan van die N.T.}

Die aktualistiese kanonbeskouing is geweldig uitgebou deur die nuwere hermeneutiek, maar nie op die spoor van Käsemann en Luther nie, maar op die voetspoor van Heidegger en Bultmann. By Käsemann het die Heilige Gees 'n geweldige rol gespeel in die verstaan van die Skrif. Die gees wat Fuchs en Ebeling adem is die gees van die ateïstiese Heidegger.

Dit is 'n opvallende kenmerk van die Nuwe Hermeneutiek dat daar so min tereg kom van die Heilige Gees ${ }^{4}$. Ook in Vorster se in. treerede word daar by die weergee van beginsels om die Nuwe Testament te verstaan niks gepraat oor die rol van die Heilige Gees nie, al sê hy in sy inleiding: die feit dat die N.T. nie sy eie verstaankodes het nie doen nie te kort ,aan die rol van die Heilige Gees by die uitleg van die Bybel nie"."

\section{3. ' $n$ Eie benaderingswyse}

'n Mens se Skrifbeskouing bepaal ten diepste ook jou wyse van Skrifverklaring. Die konsekwent-historiese metode is die alfa en die omega van die Konsekwent-Historiese Skool omdat die N.T. volgens 
hulle basies 'n gewoon menslike boek is wat in die loop van die geskiedenis soos talle ander boeke tot stand gekom het. Die teksimmanente benadering is deurslaggewend vir die wat die Nuwe Testament sien, soos alle literatuur, as 'n literêre aangeleentheid. Die kommunikasie gerigte benadering is die oplossing vir die één wat die N.T. sien as tekste oor God deur mense in menslike taal vir mense geskryf.

Daar is dus by elke Skrifverklaarder 'n bepaalde voorveronderstelling. Bultmann ${ }^{0}$ gee selfs toe dat daar nie so iets is soos eksegese sonder voorveronderstelling nie.

Die siening van die Nuwe Testament bepaal ook my benadering en resultate op deurslaggewende wyse. As uitgangspunt is my voorveronderstelling: die N.T. is die enige Woord van God. Hiermee het ek voluit 'n oog vir die feit dat die Woord onder die inspirasie van die Heilige Gees deur bepaalde mense onder bepaalde omstandighede tot ons gekom het. Ek het ook 'n oop oog vir die geskiedenis waarin die Woord oorspronklik tot die mense gekom het, omdat dit nie uit die geskiedenis uit nie, maar juis in die geskiedenis in gekom het.

Die vrae na die kanonisiteit en die inspirasie en ook na 'n eie hermeneutiek sal dus, in aansluiting by die tradisionele Gereformeerde $^{7}$ opvatting, vanuit die selfgetuienis van die Skrif en die getuienis van die Heilige Gees benader word. Maar waar Grosheide en Greijdanus nie genoeg met die openbarings-historiese karakter van die Skrif rekening gehou het nie, sal ook hierdie gesigspunt voluit honoreer word.

My mikpunt is dus om aan te toon dat die ontstaan van die Nuwe Testament bepalend is vir die verstaan daarvan.

\section{Die Heilige Gees en die ontstaan van die N.T.}

Om hierdie vraagstuk openbaringshistories te ondersoek moet daar 'n punt gevind word van waar die openbaringsgeskiedenis benader kan word. Die Bybel, sê Ridderbos", is ", het boek van de Geschiedenis van Gods verlossende en richtende daden waarvan de komst en het werk van Christus het alles beheersende centrum is". Die gesag van die prediking van Jesus, is die vertrekpunt in 'n ondersoek na die ontstaan van die N.T.

\subsection{Jesus en die ontstaan van die N.T.}

Jesus fundeer self sy gesag in sy verhouding tot sy Vader, sy selfgetuienis, sy persoon en opdrag en sy roeping en salwing ${ }^{2}$. Vir die verstaan van die werk van die Heilige Gees in die ontstaan van die N.T. is dit belangrik dat by Jesus se roeping en salwing stilgestaan word.

Jesus laat Hom deur Johannes die Doper doop (cf. Mat. 3:1315). Lukas druk die doop uit met 'n participium ( $\beta \alpha \pi \tau \iota \sigma \theta \varepsilon v \tau o s)$. Tereg sê Creed ${ }^{10}$ dat Lukas so die klem laat val op die goddelike erkenning wat Jesus hier ontvang. „Dit is my geliefde Seun in wie Ek 'n

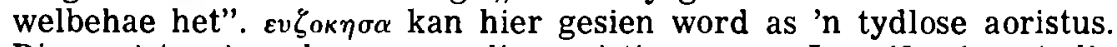
Die aoristus is gebaseer op die aoristiusse van Jes. $42: 1$ wat die 
Goddelike uitverkiesing van Israel beskryf. Die doop is dus die openbaring van die ewige uitverkiesing waardeur die Vader die Seun aangewys het as die Messias.

Die verwysing na Jes. $42: 1$ word verder uitgebrei deurdat die gebeure wat plaasvind ook slaan op wat beskryf is in Jes. 52:13$53: 12$. Jesus was bewus dat sy doop deur Johannes 'n voorafskaduwing is van die ander doop, sy dood. Daarom haas (cf. $\varepsilon v \theta v$ s in Mat. $3: 17$ ) Jesus Hom om na sy doop, sy toerusting vir sy sending te ontvang. Hierdie „toerusting” was die „Gees van God” of die „Heilige Gees".

$\kappa \alpha \tau \alpha \beta \alpha \nu \nu \omega$ (beklee) word hier gevolg deur $\varepsilon \iota s$ $\alpha \nu \tau o v$ met die betekenis "God beklee Hom met die Gees". Dit is dus 'n salwing en volgens Jes. $61: 1$ is hy gesalf ,om 'n blye boodskap te bring”. Hier word dus by die Joodse siening van Jesus se tyd aangesluit want die mededeling van die Gees beteken altyd profetiese inspirasie: God beklee Hom met die volmag om sy boodskapper te wees.

Die onbeperkte wyse waarop Jesus die Gees ontvang word in Joh. $3: 34$ beskryf. Die praesens $\delta \iota \delta \omega \sigma \nu$ (gee) wys 'n voortdurende werksaamheid aan. Nie met mate nie, maar onbeperk deel God die Gees Hom mee. Omdat God die Gees in so 'n onbeperkte sin aan Jesus skenk, spreek Jesus die Woord van God.

As Jesus oor sy lydensweg begin praat en dit betree, na die belydenis te Cesarea-Filippi, volg die verheerliking op die berg. Jesus en sy dissipels word daar herinner aan sy salwing: „Dit is my geliefde Seun". Hier is alleenlik nog 'n byvoeging:

„Luister na Hom”. Die sentrale heilsfeit van die Evangelie nl., Jesus se dood en opstanding moet met gespitste ore gehoor word deur hulle wat die evangelie sy beslag moet laat kry.

Jesus se toerusting met die Heilige Gees word dus baie sterk gekoppel aan sy prediking. Sy prediking is die sentrale punt in die openbaringsontwikkeling van die N.T.

\subsection{Die apostels en die ontstaan van die N.T.}

Christus het daarvoor gesorg dat daar vir die mededeling en oorlewing van dit wat in die volheid van die tyd gebeur het, ' $n$ formele gesagsinstansie is ${ }^{11}$. Dit wat gebeur het en dit wat gehoor en gesien is, moes gesagvol oorgedra word, want die prediking van die evangelie vir alle tye ontleen hieraan sy oorsprong en maatstaf.

Van die begin van sy optrede af sien ons dat Jesus noukeurig daarop bedag is om ander te laat deel in sy eie $\varepsilon \xi_{\text {ovorc }}$ (volmag). Daarom roep Hy die Twaalf. In die manier van roep, hulle onmiddellike gehoorsaamheid, kortom: in die feit dat Jesus hulle roep, lê die wortel van hulle gesag. In Luk. 5:10 word gesê: „Van nou af sal jy mense vang". In die participium preasens ( $\xi \omega \gamma \rho \omega v$ vang) sit die idee opgesluit van voortdurendheid, dit is 'n lewenstaak waartoe hulle geroep is.

Die dissipels is op besondere wyse toegerus vir hulle amp. Ons het reeds melding gemaak van die aкоvere avтov (luister na Hom) (Mat. 17:5 par). Hy roep sy dissipels voor sy openbare optrede begin. Meye ${ }^{12}$ sê tereg dat die doel hiervan was om Jesus se werke te sien en sy woorde te hoor. Johannes bou die apostels se gesag 
sterk op die feit van oor- en ooggetuienis ( 1 Joh. $1: 1-4$ ).

Johannes begin sy geskrif (1 Joh.) deur met groot klem die realiteit en historisiteit van die verskyning van die Seun van God in sigbare tasbare gedaante uit te spreek. Hy wat Johannes is, was op die toneel, 'n oor- en ooggetuie. Die perfecta $\alpha \kappa \eta \kappa o \alpha \mu \varepsilon v$ (gehoor) en $\varepsilon \rho \omega \rho \alpha \kappa \alpha \mu \varepsilon v$ (gesien) dui op dit wat afgeloop het, wat gebeur het, maar waarvan die resultaat nog voortduur. Die apostels het nie maar eenkeer, 'n tyd gelede gehoor en gesien nie, maar hulle het so gehoor en gesien dat dit tientalle jare daarna nog in hulle ore klink en voor hulle oog helder staan. Hy voeg hierby nog „wat ons aanskou het". Die woord $\theta \varepsilon r \mu_{\alpha} \alpha$ dui 'n fisiese en psigiese werksaamheid aan, wat 'n sien met die oog van die liggaam en van die siel is. Dit is ' $n$ liggaamlike sien met aandag en nadenke. Baie nou hiermee word „en met ons hande getas" verbind.

Die $\alpha \iota \chi^{\varepsilon \iota \rho \varepsilon s ~ l e ̂ ~ n o g a l ~ s t e r k ~ n a d r u k ~ o p ~ d i e ~ t a s b a r e ~ r e a l i t e i t, ~ d i e ~}$ sintuiglike waarneming, die historiese werklikheid. Die Apostels se prediking rus op die werklikheid, op historiese feite. En hierop beroep hulle hul. Johannes gebruik die werkwoord $\alpha \pi \alpha \gamma \gamma \varepsilon \lambda \lambda \lambda_{o} \mu \varepsilon v^{12}$ (verkondig ons aan julle 1 Joh. 1:3). Die woord het die betekenis van 'n verslag uitbring van dit wat gehoor en gesien is. Dit is egter nie maar 'n koel saaklike vertelling nie, maar dit is 'n werwende appelerende afkondiging. Hulle prediking het gesag, ook omdat dit rus op dit wat hulle werklik gesien en gehoor het.

En die Heilige Gees bevestig die getuienis van die Apostels (1 Kor. 2: 4; Hebr. $2: 4$ ).

Om hulle taak as getuies van Jesus se woorde en dade te kan vervul, stuur Jesus die Heilige Gees vanuit die hemel, die Gees wat deur die Vader beloof is (Joël $3: 1-4$ ). Hulle verkiesing tot apostels word mede aan die Gees toegeken. In Hand. 1:2 lees ons dat Jesus aan die apostels, wat $\mathrm{Hy}$ deur die Heilige Gees uitgekies het, sy bevele gegee het. Ridderbos ${ }^{14}$ sê hierby: „Het apostolaat is dus niet alleen voorwerp van die goddelijke heilsraad, niet alleen representatie van Jesus Christus, maar het heeft ook die Heilige Geest tot Auteur". Dit is ook die Heilige Gees wat hulle tot hierdie taak bekwaam (cf. Matt. $10: 18,20$; Mark. $13: 11$; Hand. $1: 8$ ) en veral ook Joh. $14: 26$; $15: 26,27 ; 16: 13-15)$. Die gebeure na die opstanding waar Jesus op hulle blaas en sê: Ontvang die Heilige Gees het die betekenis van profetiese salwing. Dit is analoog met die neerdaling van die Gees op Jesus by sy doop. Veral uit Joh. 16:13-15 kan ons aflei dat die Heilige Gees in volstrekte eenheid met Christus sy werk sal voortsit. Die openbaring van God in Jesus Christus gaan voort deur die werking van die Heilige Gees.

Juis deur die ontvangs van die Heilige Gees tree die apostels met gesag op. Petrus sê in Hand. $5: 32$ dat hulle en die Heilige Gees getuies is van die $\rho \eta \mu \kappa \tau \alpha$. Dit is nie 'n gelykstelling tussen die Apostels en die Heilige Gees nie. Calvyn ${ }^{15}$ sê dit is 'n verseëling om hulle leer goed te keur. In die $\mu \alpha \rho \tau v \rho \varepsilon \iota v$ (getuienis) van die Heilige Gees oor die Jesus word die werk van Jesus voortgesit (cf. Joh. 15:26) ${ }^{16}$.

Die getuienis van die apostels is nie bloot 'n verslag van die openbaring, soos Barth ${ }^{17}$ wil nie. Hulle is openbaringsgetuies. Hulle prediking is openbaring. Jesus sê: „Wie na julle luister, luister na My" 
(Luk. $10: 16$ cf. Joh. $20: 21$ ). In Hebr. $2: 2$ e.v. word die apostels as draers van die openbaring vergelyk met die engele van die $\mathrm{Ou}$ Verbond. Ridderbos ${ }^{81}$ sê van die perikoop: ,zoals het Oudtestamentische openbaringswoord door bemiddeling van de engelen is gesproken en rechtskragtig ( $\left.\beta \varepsilon \beta \alpha \beta_{0}\right)$ is gebleken, zo is ook het Nieuwtestamentische heil, dat eerst door de Here ise verkondigd, door de apostelen, die hen gehoord hebben, op een rechtsgeldige wijze bevestigd $(\varepsilon \beta \varepsilon \beta \varepsilon \tau \omega \theta \eta)$ '". Die apostels is dus nie slegs getuies of predikers in die algemeen kerklike sin van die woord nie; hulle woord is openbaringswoord, dit is vir eens en vir altyd gesagvol. Met reg kon hulle daarop aanspraak maak dat hulle prediking nie 'n mens se woord is nie, maar God se Woord. (1 Thess: 2:6,13).

\section{Die oorlewering ${ }^{19}$}

By die prediking van die apostels moet ons eerstens dink aan die mondelinge voordrag. Ook as hulle skryf (briewe skryf) stel hulle die gesproke woord op een vlak met die geskrewe. Paulus sê: „.. . hou julle aan die voorskrifte wat julle geleer is of deur ' $n$ woord of deur 'n brief van ons'. (11 Thess. $2: 15 \mathrm{~b}$ ).

Waar in 2 Petr. $3: 15$ die eerste spore gevind word van 'n versameling van apostoliese geskrifte word die mondelinge woord van die apostels ook gelyk gestel met dié op skryf (cf. 2 Petr. 3:2; 1 Petr $1: 12$ ).

Dit gaan dus eerstens oor die mondelinge oorlewering. Hier staan die begrip $\pi \alpha \rho \alpha \delta$ oots sentraal. Lukas beroep hom in sy proloog op die oorlewering van die ooggetuies (Luk. 1:2). Judas praat van die geloofsinhoud wat oorgelewer is (vs. 3). Paulus wys sy lesers in sy briewe telkens op dit wat hy aan hulle oorgelewer het toe hy die evangelie (mondeling) verkondig het. (cf. 1 Kor. $15: 3$; 1 Kor. $11: 23$ ).

In die openbaringshistoriese wording van die Nuwe Testamentiese Kanon gaan die oorlewering in die meeste gevalle die te boekstelling vooraf. Die N.T. is vir 'n groot deel die neerslag van voorafgaande mondelinge oorlewering.

Nou wil baie dat die mondelinge oorlewering buite die grense van die openbaringsgeskiedenis val en daarom blootgestel is aan die onnoukeurighede van die menslike en kerklike tradisie. Maar die Nuwe Testamentiese oorleweringsbegrip is baie sterk bepaal deur die Joodse begrip: Die begrip kry sy gesag van die karakter van die oorleweringstof self en die amp van die wetsleraars. ${ }^{20}$.

Hoeseer die mondelinge oorlewering binne die grense van die openbaringsgeskiedenis val, blyk uit die bekende „oorleweringsperikoop" in 1 Kor. $15: 1-3$. "Ek maak julle die evangelie bekend wat ek aan julle verkondig het, wat julle ook aangeneem het $(\pi \alpha \rho \varepsilon \lambda \alpha \beta \varepsilon \tau \varepsilon)$, waarin julle ook staan ..... (vs. 1).

Veral vs. 3 is bepalend: "Want in die eerste plek het ek aan julle oorgelewer $(\pi \alpha \rho \varepsilon \delta \omega \kappa \alpha)$ wat ek ook ontvang het $(\pi \alpha \rho \varepsilon \lambda \alpha \beta o \nu)$.."

Paulus wys dus, soos ook in 1 Kor. $11: 23$, dat hy enersyds self die ontvanger is, andersyds die draer van die oorlewering. Dit word beklemtoon met die woordjie „ook" (wat ek ook ontvang het) wat in werklikheid beteken: op my beurt. Die oorlewering waarvan Paulus hier praat verteenwoordig 'n gesaghebbende persoonlike in- 
stansie, nl. die apostels. Hulle dra die oorlewering kragtens die gesag wat hulle van Christus ontvang het. Daarom kan met oortuiging gesê word dat die oorlewering wat aan die apostels as getuies van Christus toevertrou is, niks anders is as gesagvolle verkondiging. Daarom word die oorlewering ook ,leer” genoem (Rom. 0: 17 e.a.). Ook Lukas (1:3) en Markus (1:1: die prediking van die apostels soos dit in opdrag van Christus oorgelewer is) bou hulle evangelie op hierdie oorlewering.

Die oorlewering word gelyk gestel met die apostels se evangelie ( 1 Kor. 15:1) wat jy nie as mensewoord moet ontvang nie, maar soos dit werklik is, as Woord van God (1 Thess. 2:13). Paulus bring dan ook die voortgang en bewaring van die oorlewering in verband met Christus self (Gal. 1:12). Hy het die openbaring van Jesus Christus ontvang. As hy in 1 Kor. 11 en 15 praat van dit wat hyself by oorlewering ontvang het, verwys hy le na dit wat hy van die ander apostels ontvang het. Hulle (en hy) is die sjelochim van Jesus Christus.

Van besondere belang is dat Paulus die voortgang van die oorlewering aan Christus toeskryf. 1 Kor. $11: 23$. „Want ek (met klem $\varepsilon \gamma \omega \gamma \alpha \rho$ ) het as oorlewering van die Here ontvang, dit wat ek ook aan julle oorgelewer het ...."

\subsection{Die oorlewering as Skrif.}

Die Nuwe Testament self gee aan die mondelinge en skriftelike oorlewering dieselfde gesag (2 Thes. $2: 2,15$ ). Uit sommige uitsprake in die N.T. kan afgelei word dat die op-skrif-stel van die oorlewering, juis die vorm is waarin die gemeente gebind word aan die woord van die apostels. Juis met hierdie doel voor oë word die oorlewering van die apostels op Skrif gestel.

1 Kor. 15: Paulus skryf uitvoerig en duidelik oor die opstanding. Hy doen dit om die oorlewering van die opstanding op skrif te kry en te bevestig. Hy sê nie iets nuuts nie (1 Kor. 15:1). Dit gaan vir hom daarom dat die gemeente die oorlewering vashou „op die wyse waarop ek dit aan julle verkondig het". $\tau \iota \nu \iota ~ \lambda o \gamma \omega$ beteken hier ,in die bewoordinge, in die formuleringe". Dit is 'n bepaalde geykte uitdrukking. Nie net wat gesê word is belangrik nie, maar ook hoe dit gesê word. Ook in watter vorm dit gesê word. Hier word geen onderskeid gemaak tussen vorm en inhoud nie. Die op skrif stel vind dus plaas om dit te bevestig wat gebeur het. Daar kan nou nie vervalsing kom nie. Dit was ook Lukas se motief met die evangelie op Skrif $(1: 1-4)$.

Van die begin af moes die skriftelike oorlewering ontvang word as met goddelike gesag beklee. Die gesag van die oorlewering van die apostels op skrif word verbind met die Ou Testamentiese boeke. Paulus wil dat sy briewe reeds in die tyd waarin hy dit skryf in die samekomste van die gemeente gelees word ( 1 Thes. $5: 27$; Kol. $4: 16$ ) net soos dit met die geskrifte van die O.T. gebeur het. So ook die Openbaring $(1: 3)$ van Johannes. Die terminus technicus waarmee Johannes die 0.T. aanhaal. $(2: 17 ; 6 ; 31 ; 45 ; 10: 34 ; 12: 14 ; 15: 25)$ gebruik hy ook wanneer hy aan die slot van sy boek vir sy eie werk die geloof van sy lesers vra. Ook reeds in die Nuwe Testament word 
die briewe van Paulus met die O.T. skrifte op een lyn geplaas ( 2 Petr. $3: 16$ ).

Ridderbos $^{21}$ maak tereg dié konklusie: „dat de autoriteit van God zich niet slechts als kanon in de grote werken Gods in Jezus Christus handhaaft, maar zich ook uitstrekt tot de mededeling daarvan in de woorden en in de geschriften van de daartoe in het bezonder aangewezen en gequalificeerde dragers en instrumenten der goddelijke openbaring. Daarbij ontvangt de door hen vertegenwoordigde schriftelijke traditie, naar analogie van de Schriften van het Oude Testament, de betekenis van fundament en maatstaf van de komende kerk".

\subsection{Konklusies}

2.5.1. Christus en sy apostels ontvang elk, voor hulle openbare optrede, die salwing met die Heilige Gees, die toerusting vir hulle profetiese taak. Die Heilige Gees bly die groot Outeur van die Nuwe Testament. Die hele Skrif is deur God ingegee. Die Heilige Gees het God se gedagtes in die Bybelskrywers se gedagtes ,ingeblaas” sodat hulle in hulle eie woorde God se Woord geskryf het.

Die belydenis van die inspirasie of theopneustie word bevestig deur die openbaringshistoriese ondersoek na die ontstaan van die N.T.

2.5.2. Die N.T. kom nie as 'n komplete boek meteens uit die hemel nie. Die N.T. moet in mensetaal getolk word. Daarom is daar 'n proses, 'n geskiedenis. Oog. en oorgetuies vertel, daar ontstaan mondelinge oorlewering, die apostels verwerk en interpreteer die gebeure en steeds deur die leiding van die Heilige Gees word die oorlewering op Skrif gestel. Maar die proses, die geskiedenis van die ontstaan van die N.T. val binne die grense van die openbaringsgeskiedenis.

2.5.3. Uit die besondere wyse waarop die N.T. ontstaan (so die hele Skrif) kom die uniekheid daarvan nog sterker na vore.

\section{Die Heilige Gees en die verstaan van die N.T.}

\subsection{Eie beginsels vir die verstaan}

Omdat die N.T. uniek is, kan die verstaanskodes van ander geskrifte nie voluit op die NT toegepas word nie. Natuurlik word die NT in Grieks, in 'n bepaalde tydperk en deur bepaalde mense met 'n eie aard geskryf. Daar sal dus taalkundige, kultuurhistoriese en literêre aspekte wees wat raakpunte het met ander geskrifte.

Maar die NT kan net verstaan word as die verklaringswyse uit die NT self verkry word. Greijdanus noem daarom sy bekende werk oor die wyse van Skrifverklaring ,Schriftbeginselen ter Schriftverklaring 2 .

\subsubsection{Die Heilige Gees en die verklaring van die N.T.}

Vir die uitlê van die Skrif is daar meer nodig as die natuurlike verstand. Dit leer Petrus (2 Petr. 1:19-21): ".... julle (moet) 
veral dit weet, dat geen profesie van die Skrif 'n saak van eie uit-

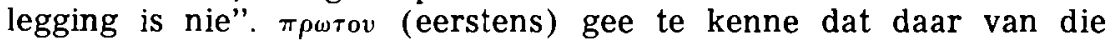
regte verstaan van die profetiese woord nie sprake kan wees wan. neer daar nie gereken word met die eise van dit wat in die vers gesê word nie. Die participium praes. $(\gamma \iota v \omega \sigma \kappa o v \tau \varepsilon)$ wys daarop dat jy altyddeur daarmee moet reken.

Waarmee moet jy altyd rekening hou?

$\iota \delta \iota \alpha s$ (eie) het hier betrekking op die leser. Met die woorde word alle willekeurige eiemagtige uitlegging van die profete veroordeel. Geen eksegese mag volgens die eie denke en wense plaasvind, sonder die verligting en leiding van die Heilige Gees. „Een „eigen" of „eigenmachtige" uitlegging is een uitlegging, waarin de menselijke geest de boventoon voert"23. Die profete (en die Skrif) kan net verstaan word as dit vanuit dieselfde Gees verstaan word, Hy wat die profete tot spreek gedryf het. die passiwiteit van die profete aan. Die inisiatief gaan nie van hulle uit nie. Hulle word tot spreek gebring, gedryf. Die praes. part. laat sien dat hulle nie net aangespoor word om te spreek nie, maar ook tydens hulle sprake of solank hulle profeteer, word hulle daartoe gedryf. Die drywing gaan al die tyd deur. Hierdie felt bepaal die uitlegging. Die verstaan van die Skrif is altyd onder leiding van die Heilige Gees (ook terwyl gepreek, geluister, diskussies gevoer, lesings gehou word, ens.).

Hoekom is Petrus (en ander in die N.T.) so uitgesproke oor die feit dat die Heilige Gees dié Eksegeet van die N.T. is?

Paulus gee in 1 Kor. $2: 10$ e.v. die antwoord. Die Gees laat ons dit sien wat vir die Sanhedrin en Pilatus verborge gebly het. Die menslike oog kon nie ontdek dat die gekruisigde Jesus die Here van die Heerlikheid is nie. Maar die Gees deursoek alle dinge ook die dieptes van God. Net die Gees van God ken die diepte van God. Want karakteristiek vir die diepte van God is die ondeurgrondelikeheid en ondeurdringbaarheid (onnaspeurlikheid) daarvan (Rom. 11 : 33 e.v.) Slegs God se eie Gees het toegang. ,So weet niemand wat in God is nie, behalwe die Gees van God", sê Paulus in vs. 11. En nou die wonder: ons het God se Gees as Inwoner in ons hart en Hy laat ons deel in sy kennis van God (cf. Rom. $8: 23 ; 2$ Kor. 1:22). God se Gees gee aan die gemeente kennis van sy genadewerk. Ons wat in die wonderwêreld van genade deur die wedergeboorte geplaas is, maak onder leiding van die Gees ontdekkings. Hy is ons Gids wat ons rondlei en dit goed doen, omdat $\mathrm{Hy}$ weet wat $\mathrm{Hy}$ ons moet laat sien. (Joh. 16 : 13 e.v.. Hy spreek nie uit Homself nie, maar Hy spreek alles wat Hy hoor).

Die Heilige Gees leer ons (1 Kor. 2:13) om die geestelike dinge met geestelike te vergelyk. $\sigma \nu \gamma \kappa \rho \iota \nu \omega$ wil as par. praes. die werk van meer as een gelowige aantoon. Hulle moet saam ( $\left.\sigma \gamma_{\kappa} \rho \nu \omega\right)$ die geestelike dinge vergelyk, verklaar om deur hulle gesamentlike werk dieper daarin in te dring (GTV. Werkgemeenskappe, Bybelstudiegroepe.).

Die Heilige Gees is dié Bybelverklaarder. God laat nie net die heilsdade in die geskiedenis plaasvind nie, maar sorg ook deur sy Heilige Gees dat ons 'n betroubare berig daaroor ontvang en - 
deur dieselfde Heilige Gees - dat ons ook die berig reg verstaan. Hoe laat die Heilige Gees ons die berig reg verstaan?

Die werkwoorde in Joh. $14: 26$ en 16:13 gee die sleutel: „Hy

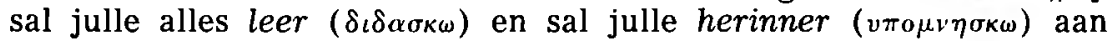
alles wat Ek (Jesus), vir julle gesê het" en „Hy sal julle in die hele waarheid lei $(\delta \delta \eta \gamma \varepsilon \omega)$. Die Heilige Gees sit die werk voort. Die Gees sal dus onderwys, saaklik uiteensit en die implikasies van die heilsgebeure aanwys, deurdring tot die diepere sin en dit vir ons ontvou. $-\delta \iota \delta \alpha u k \omega$.

In 1 Kor. 1 : 10 gebruik Paulus 'n praes. vir die ondersoek-werk van die Gees. Dit is altyd sy werk cf. Joh. $5: 17$. Hy ondersoek nie omdat Hy nie ken nie. Nee, deurgrondig, ondersoek is die aksie van die Gees, sy voortdurende werksaamheid, want daarmee saam gaan die openbaring aan die mens.

Die Gees leer deur te herinner. Die k $\alpha \iota$ (Joh. 14:26) tussen $\delta \iota \delta a \zeta \varepsilon \iota$ (leer) en $v \pi \mu_{\mu \nu \eta \sigma \varepsilon \iota}$ (herinner) het die betekenis van 'n dubbelpunt. Die Gees herinner aan alles wat Jesus self geleer het. „16:13 does not merely repeat $14: 26$; it developes it. Whereas $14: 26$ refers more confirmation of the preaching of Jesus, $16: 13$ has in view its deepening and definitive completion". ${ }^{24}$ Daarom gebruik Johannes hier vir lei $\delta \delta \eta \gamma \varepsilon \omega$. Die Gees lei, begelei die eksegeet soos 'n gids die weg aanwys.

Petrus leer die gelowige om te wag vir die begeleiding. Hy sê ons moet op die woord ag gee (2 Petr. 1:1) die aandag daarop gevestig hou. Dit moet met inspanning en volharding geskied totdat die genadige lig in die hart opgegaan het. Die woord moet oordink word, bestudeer word, want die Gees werk nie los van die Woord nie.

\subsubsection{Die openbaringsgeskiedenis en die verstaan van die N.T.}

Direk na die uitstorting van die Heilige Gees preek Petrus. In Hand. 2 het ons 'n duidelike voorbeeld van die leiding van die Heilige Gees in die eksegese.

Petrus haal o.a. aan uit Joël 2, Ps. 16 en Ps. 110. Hy vergelyk Skrif met Skrif. Tog kom daar iets by. Dit blyk reeds uit sy eerste aanhaling uit Joël 2. Hy haal Joël so aan „In die laaste dae, spreek God, sal Ek ... "Joël sê: „En daarna . . " Die openbaringshistoriese moment kom duidelik na vore.

As Petr. die aanhaling voltooi het, spreek hy sy hoorders weer aan. Dan volg 'n uiters belangrike hermeneutiese reël: „Jesus . . . het julle gekruisig. Hom het God opgewek". (vs. 22, 23). Die sentrale punt van die openbaringsgeskiedenis word aangedui: die koms van die Seun van God.

Vir die eksegese is dit van kardinale belang om alles vanuit die koms Christus te besien. Nog nader dui Petrus dit aan: „wat julle gekruisig het. Hom wat God opgewek het". Die dood en opstanding van Jesus Christus beheers die eksegese van enige Skrifgedeelte. Dit is die hoek van benadering vir die eksegeet wat deur die Heilige Gees geleer, herinner en gelei word.

Ook die verklaring van Ps. 2 in Hand. 4:25 e.v. wys dieselfde 
koers aan. Die teken dat die Heilige Gees die Eksegeet is, is die feit dat die plek geskud word.

Dit sou dus insiggewend wees vir die hermeneutiek om die hoofmomente van die openbaringsgeskiedenis te ontleed en daaruit beginsels vir die eksegese te trek.

\section{Ten slotte}

Die openbaringshistoriese karakter van die ontstaan van die NT is bepalend vir die verstaan van die NT. Want die groot Outeur is ook die groot Eksegeet. Wie die N.T. werklik wil verstaan, moet dit in regte gees benader - in dié Gees.

\section{Ander moontlike studierigtings}

5.1. Die ontstaan en verstaan van die O.T.

5.2. Die hoofmomente van die openbaringsgeskiedenis bied beginsels vir die hermeneutiek.

Gelewer voor die GTV Potchefstroom 22 Mei 1978.

1 Käsemann, Ernst: „Begründet der neutestamentliche Kanon die Einheit der Kirche?" in „Das Neue Testament als Kanon”, Vandenhoeck Rupricht Göttingen p. 124 e.v.

2 cf. Ebeling, G: „Evangelische Evangelieauslegung” Darmstadt 1962 p. 368.

3 Vorster, W. S. ,'n Ou Boek in 'n nuwe wêreld - gedagtes rondom die interpretasie van die N.T." Unisa 1977 p. 22, 23.

4 cf. Fuchs, Ernst in "The New Testament and the Hermeneutical Problem" in "New Frontiers in Theology" Vol II "The New Hermeneutic" Harper \& Row, New York 1964 ook Ebeling, G. in „Wort Gottes und Hermeneutik" in Zeitschrift für Theologie und Kirche. Vol. 56 Tubingen 1959.

5 Vorster, W. S. a.w. p. 5

6. Bultmann, R.: „Ist voraussetzunglose Exegese möglich?" in Theologische Zeitschrift Vol. 13 Basel 1957 p. 409 e.v.

Bultmann sê egsegese is nie sonder voorveronderstelling (,voraussetzunglos') nie, ondat dit as historiese interpretasie die metode van die histories-kritiese ondersoek veronderstel. Daar is 'n "Lebenzussammenhang" van die cksegeet met die subjek warmee die Bybel erns maak en uit hierdie korrelasie vloei 'n „Vorverstăndnis". Hierdie „Vorverständnis". is nie afgesluit nie, maar is oop sodat daar 'n „existentielle Begegnung" met die teks kan wees en 'n „existentielle Entscheiding". Sy voorveronderstelling is dus dat die eksistensiefilosofie die begince!s gee vir die verstaan en verklaar van die N.T. Vandag se kommunikasicgerigte eksegese is net 'n nuwe vorm, 'n ander voorveronderstelling, van buite die Skrif vir die verk'aar van dic N.T.

7 cf. Greijdanus, Sj. „Schriftbeginselen ter Schriftverklaring” Kok 1946 Grosheide, F. W. „Algemeene Canoniek van het Nieuwe Test. „Bottenburg 1935 Amsterdam.

8 Ridderbos, H.: „Feilloosheid, onfeilbaarheid, autoriteit” in „Het Woord, het Rijk en onze verlegenheid" Kok, Kampen 1968, p. 64. 
9 cf. De Klerk, B. J.: „Die gesag van die prediking van Jesus" Th.M-verhandeling. P.U. vir C.H.O. 1975,

10 Creed, J. M.: "The Gospel according to St. Luke. The Greek text with introduction, notes and indices". Macmillen New York 1960 (1e uitgawe 1930).

11 cf. Ridderbos, Herman: „Heilsgeschiedenis en Heilige Schrıft van het nieuwe testament. Het gezag van het nieuwe testament" Kok, Kampen 1955. p. 34 e.v.

12 cf. Meye, Robert, P : „Jesus and the Twelve”, Eerdmans, Grand Rapids, 1968 p. 50.

14 Ridderbos, Herman: „Heilsgeschiedenis . . . " p. 38.

15 Calvyn, Johannes: „De Handelingen der Apostelen” vertaal deur G. Wic. lenga 1970-uitgawe p. 188.

16 Oor die betekenis van dic woord "Apostel" (die Sjaliach-figuur) kan breedvoerig gehandel word. Hier word beperk tot die Heilige Gees en die gesag van die Apostels.

17 cf. Runia, Klaas: „Karl Barth's doctrine of Holy Scripture”, Grand Rapids, 1962 pp. $34 \& 35$.

18 Ridderbos, Herman: Heilsgeschiedenis ..." p. 39.

19 By 2.3. en 2.4. word ruimskoots gebruik gemaak van Ridderbos se „Heilsgeschiedenis ..." p. 40 e.v.

20 cf. Kittel: „Die Probleme des palästinischen Spätjudentums und das Urchristentum" 1962. p. 64.

21 Ridderbos, H.: „Heilsgeschiedenis . . " p. 57, 58.

22 Die werk van Greijdanus en Grosheide oor die hermeneutiek het hulle gebreke. Grosheide benader die hermeneutiek sterk filosofies. Greijdanus beklemtoon die waarheid dat Skrif met Skrif vergelyk moet word maar neem nie die openbaringsgeskiedenis se gang in ag nie. By albei word nie veel aandag aan die Heilige Gees as eksegeet gegee nie.

23 Bolkestein, M. H : De Brieven van Petrus en Judas" in die reeks „De Prediking van het N.T." Callenbach, Nijkerk 1972. p. 269.

24 Michaelis, Wilhelm: In "Theological Dictionary of the New Testament" Vol. V. edited by Gerhard Friedrich oor , $\delta \delta \eta \gamma \varepsilon \omega$. 